to treatment. The two patients who failed to respond clinically to the agonist were subsequently found to have low serum concentrations of luteinising hormone, follicle stimulating hormone, and testosterone and showed no endocrine response. This suggests either absent gonadotrophes or deficient receptors of gonadotrophin releasing hormone. Of these two patients, one was found by computed axial tomography to have a partially empty pituitary fossa, which may possibly explain the lack of endocrine response and absence of clinical improvement.

All five patients in whom the agonist was the primary treatment responded. Interestingly, three patients who had previously relapsed while receiving endocrine treatment responded to the agonist, suggesting that it might have an additional effect other than its lowering action on testosterone concentration, and possibly reflecting its additional considerable suppression of serum gonadotrophin concentration.

The results observed in this study compare favourably with preliminary reports from other centres using other analogues of gonadotrophin releasing hormone. ${ }^{112}$ Use of these superactive agonists might well provide a safe and more effective treatment for adenocarcinoma of the prostate than any hitherto available. Longer term trials are clearly needed.

\section{References}

' Hutchinson GB. Incidence and etiology of prostate cancer. Urology $1981 ; 17$, suppl 3:4-10
${ }^{2}$ Whitehead ED. Management of prostate carcinoma. NY State $\mathcal{f}$ Med $1981 ; 81: 1481-5$.

${ }^{3}$ Yen SSC, Tsai CC, Naftolin F, Vandenberg G, Ajabor L. Pulsatile patterns of gonadotrophin release in subjects with and without ovarian function. $\mathcal{F}$ Clin Endocrinol Metab 1972;34:671-5.

${ }^{4}$ Pinto H, Wajchenberg BL, Linia FB, Goldman J, Comaru-Schally AM, Schally AV. Evaluation to the gonadotrophic responsiveness of the pituitary to acute and prolonged administration of $\mathrm{LH} / \mathrm{FSH}$ releasing hormone (LH-RH) in normal females and males. Acta Endocrinol $1979 ; 91: 1-13$

${ }^{5}$ Linde R, Doelle GC, Alexander N, et al. Reversible inhibition of testicular steroidogenesis and spermatogenesis by a potent gonadotropin-releasing hormone agonist in normal men. $N$ Engl f Med 1981 ;305:663-7.

${ }^{6}$ Union Internationale Centre de Cancer. TNM classification of malignan tumours. 3rd ed. Geneva: International Union against Cancer, 1978.

Marshall JC, Anderson DC, Fraser JR, et al. Human luteinising hormone in man. Studies of metabolism and biological action. $\mathcal{f}$ Endocrinol 1973;56:431-9.

${ }^{8}$ Burke CW, Galvao-Teles A, Fraser TR. Clomiphene citrate in man: increase of cortisol, luteinising hormone, testosterone and steroid binding globulins. $\mathcal{F}$ Endocrinol $1972 ; 53: 261-76$.

${ }^{9}$ Ghanadian RJ, Lewis JG, Chisholm GD. Serum testosterone and dihydrotestosterone changes with age in rat. Steroids 1975;25:753-62.

10 Smith $\mathrm{PH}$, Akdas A, Mason $\mathrm{MK}$, et al. Hormone therapy in prostatic cancer. Acta Urol Belg 1980;48:98-105.

11 Tolis G, Ackman D, Stellos A, et al. Tumour growth inhibition in patients with prostatic carcinoma treated with luteinising hormone releasing hormone agonists. Proc Natl Acad Sci USA 1982;79:1658-62.

12 Borgmann V, Hardt W, Schmidt-Gollwitzer M, Adenauer H, Nagel R. Sustained suppression of testosterone production by the luteinising hormone releasing hormone agonist Buserelin in patients with advanced prostate carcinoma. Lancet 1982 ; i :1097-9.

(Accepted 28 March 1983)

\title{
Bulimia nervosa, binge eating, and psychogenic vomiting: a controlled treatment study and long term outcome
}

\author{
J HUBERT LACEY
}

\begin{abstract}
An "epidemic" prevalence of binge eating and vomiting (bulimia nervosa) has been reported, and treatment has been claimed to be difficult. This paper describes a short term outpatient treatment programme of eclectic orientation capable of being conducted by non-specialist staff, under medical supervision, in local centres. The treatment programme was evaluated in a controlled trial and in long term follow up. In 30 women with severe bulimia the treatment programme significantly reduced their incidence of dietary manipulation without producing weight gain, weight disorder, or neurotic illness. After treatment all the women had fewer symptoms; 24 stopped binge eating and vomiting at the end of treatment, and a further four stopped shortly afterwards. During formal follow up 20 showed no dietary abuse and a further eight reduced their attacks to an average of three episodes a year: all judged treatment to be a success.
\end{abstract}

Pretreatment indicators of poorer prognosis include

\footnotetext{
Academic Department of Psychiatry, St George's Hospital Medical School, London SW17 ORE

J HUBERT LACEY, MPHIL, MRCPSYCH, senior lecturer and honorary consultant
}

alcohol abuse and a history of anorexia nervosa. Married patients experienced marital difficulties or illness in the spouse.

\section{Introduction}

Bulimia nervosa $a^{1}$ or the bulimic syndrome is a recently described disorder characterised by powerful and intractable urges to overeat, particularly carbohydrate foods. The fatness, ordinarily the result of such binge eating, is thwarted by psychogenic vomiting, purgation, or intermittent periods of starvation, so that the patient (normally a woman) remains within her normal range for weight. ${ }^{2}$ The bulimic episodes are associated with great distress and marked by feelings of loss of control, self disgust, anger, and depression. ${ }^{3}{ }^{4}$ Diagnostic criteria have been established by Russell ${ }^{1}$ and by the American Psychiatric Association. ${ }^{5}$

The syndrome is heterogeneous, for although many patients give a history of having had anorexia nervosa ${ }^{16}$ most of the patients of normal weight have not. ${ }^{\text {? }}$

Bulimia nervosa occurs overwhelmingly in women. Its prevalence in general populations is unknown, but symptoms associated with it are common. ${ }^{6} 8-10$ Reports from clinics $^{3}$ ? and surveys of groups at risk ${ }^{1011}$ suggest that the condition is reaching epidemic proportions. Certainly treatment centres are overwhelmed with referrals, and the letters suggest that there are many patients, previously undetected, who are judged by both their general practitioner and themselves to be ill and who have no locally available treatment. 
Of the few reports of treatment for patients with bulimia, ${ }^{12}$ many suggest the need for prolonged, and hence expensive, inpatient treatment ${ }^{6}$ or specialist, and usually scarce, skill. ${ }^{13}$

Awareness of the numbers of patients afflicted and of their need for local treatment by perhaps limited resources led to the development of this short outpatient treatment programme. This paper describes the features of the programme, a controlled evaluation of it, and the long term outcome after up to two years.

\section{Patients and methods}

Design-Thirty women were treated in six groups of five. All patients fulfilled the criteria of bulimia as set down in the Diagnostic and Statistical Manual of Mental Disorders ${ }^{5}$ and by Russell. ${ }^{1}$ Each group contained one patient who had "recovered" from previous anorexia nervosa and was now at a normal body weight, the diagnosis of which was based on criteria established by Feighner ${ }^{14}$ and Crisp. ${ }^{15}$ The other four patients in each group gave no history of anorexia nervosa, major weight loss, or phobia of normal body weight. After initial physical and psychiatric assessment lasting two weeks the patients were allocated alternately to the treatment programme or to a non-treatment control programme, both of which lasted 10 weeks and were followed by a two week assessment period. Those who were initially placed into the control programme then entered the treatment programme and underwent another two week assessment immediately afterwards.

Measures-The eating behaviour and mood state of the patients were monitored by a daily symptom diary and mood analogue scales. ${ }^{16}$ This was done not only during the 10 week treatment programme but also during the two two week assessment periods before and immediately after both the treatment and control programmes. The patients were also assessed by a psychiatrist using a standard symptom checklist in formal follow up clinics which occurred one and three months after the end of the treatment programme and, thereafter, at every three months for up to two years.

Criteria-Patients were selected who fulfilled the diagnostic criteria, were aged over 17 and under 45, were clinically suitable for outpatient treatment - that is, were not suicidal, etc-and agreed, in advance, to the demands of the programme. The sample were consecutive acceptors: seven other patients were seen and either decided not to pursue treatment or did not fulfil selection criteria.

The patients were aged from 21 to 37 and gave a history of both bulimia and psychogenic vomiting for 3 to 18 years. The vomiting (mean number of episodes $3 \cdot 78 /$ day) and bulimia (3.32/day) were severe. The mean presenting weight of the sample was $3 \cdot 2 \%$ above the patients' matched population mean weight. ${ }^{17}$ Five of the patients were married; none of them had children. Their clinical features have been described elsewhere. ${ }^{6}{ }^{718}$

\section{THE TREATMENT PROGRAMME}

The treatment programme took place on one half day a week for 10 consecutive weeks. Each programme was conducted by two therapists. The therapists (both medical and non-medical) had knowledge of psychiatric patients and psychiatric methods; they were familiar with group work but had had no specialist training in group techniques. Each of the five patients in each group attended for half an hour's individual session with one therapist before both therapists and patients met together for a group session lasting one and a half hours. The individual session initially used simple behavioural and counselling techniques before moving on to insight directed psychotherapy. The group was insight directed throughout. The aim was that the treatment would remove all symptoms without allowing the development of a weight disorder and that it would give enough psychiatric help for the patient to deal herself with emotional and relationship problems or, at worst, allow her to seek help from the general psychiatric services without being encumbered by an eating disorder.

The programme consisted of a graduated contract, a series of structured controls, and formal opportunities for therapy.

The contract was made between patient and therapist. It was developed and agreed during each individual session and written down by the patient herself in her dietary diary (see below) and a copy made by the therapist in the notes. Before the onset of treatment, the patient contracted, firstly, to attend the 10 sessions and their related groups. Secondly, she agreed to maintain her presenting weight throughout the 10 weeks of the programme. Thirdly, she contracted to eat the prescribed diet (see below). This meant eating three meals a day at set times; the times took into account prearranged social events. From the beginning of the treatment programme the patient was encouraged to stop eating in binges and vomiting. Though this was rarely possible, the patient was encouraged to reduce then stop the bulimia, each stage being marked by its incorporation into the contract. If bulimia occurred she was encouraged, then contracted, not to vomit. Most importantly, she contracted to eat the next prescribed meal irrespective of the proximity of the previous binge.

Controls-Five controls were built into the programme. Most importantly, the patient used the rigid structure of the treatment programme itself and the transference relationship (see Discussion), but three other stratagems were also used. Firstly, the therapist gave the patient each week a dietary diary. The written instructions stated that she was to carry the diary on her person everywhere (including the lavatory) throughout the week until it was handed back and kept by the therapist at the beginning of the following individual session. Each double page in the diary was divided into columns into which the patient was instructed to record the quantity and description of all food and drink consumed, the time when eaten, and the incidence of bulimia, psychogenic vomiting, and laxative abuse. She also recorded her feelings and thoughts in temporal sequence to the details of food consumed or eating symptoms displayed. She was encouraged to explain why she was binge eating or vomiting at that particular moment. The second stratagem of control was a diet sheet, which outlined a prescribed diet structured into meals. The quantity of bread, potatoes, and other "carbohydrate" foods which the patient contracted to eat was clearly marked. The patient had a choice, however, in both variety and quantity, of other foods. The aim was to control her carbohydrate intake, not the energy value of all the food eaten. The patient was told that she could not change her diet without reference to her therapist. The last control was the weekly weighing on the same scales by the same person (the therapist) at roughly the same time each week.

Therapy-Three formal treatments were built into the programme -firstly, the diary, which was "available" throughout the day; secondly, the individual session; and, thirdly, the group. The aim of therapy was the recognition and delineation of emotional and social factors which were associated with, or generated by, the patient's symptoms. The patients were encouraged, particularly within the mutual support provided by the group, to experiment with new ways of dealing with their feelings and interpersonal difficulties. The aims of the group were formulated into a handout which was given to the patient before the treatment programme.

\section{THE CONTROL PROGRAMME}

The control programme lasted the same period as the treatment programme. The same initial assessment preceded both programmes. The two week assessment periods, before and after the programmes, used the same questionnaires, scales, and dietary diaries. No formal contact was made during the control programme: the patients were not seen in the clinic or telephoned.

\section{Results}

Table I shows that the eating habits of the 15 (even numbered) patients who went directly into the treatment programme were similar to those of the group of 15 (odd numbered) patients who first entered the control programme, any differences being non-significant (Mann Whitney).

Impact of the control programme-The control programme had no demonstrable effect on the incidence of bulimia or psychogenic vomiting (table II). Though individual fluctuations occurred, the patients reported a mean of 45 bulimic episodes during the two week assessment period before the control programme and just under a mean of 47 episodes afterwards. Similarly, the incidence of vomiting did not significantly change over the 10 week control period.

Impact of treatment programme-The treatment programme, however, had a significant impact on the incidence of both bulimia and vomiting (table I). A mean of 47 bulimic attacks were reported during the 14 days before the treatment programme. This fell to a mean of just over two attacks during the two weeks after assessment ( $p<0.01$, Mann Whitney). The incidence of psychogenic vomiting 
TABLE I-Incidence of dietary abuse in each of 30 patients over 14 days before and after treatment

\begin{tabular}{|c|c|c|c|c|}
\hline \multirow{2}{*}{$\begin{array}{l}\text { Case } \\
\text { No }\end{array}$} & \multicolumn{2}{|c|}{ Bulimia } & \multicolumn{2}{|c|}{ Vomiting } \\
\hline & Before treatment & After treatment & Before treatment & After treatment \\
\hline 1 & 120 & 28 & 136 & 36 \\
\hline 2 & 45 & 0 & 54 & 0 \\
\hline 3 & 31 & 0 & 39 & 0 \\
\hline 4 & 34 & 0 & 41 & 0 \\
\hline 5 & 27 & 0 & 35 & 0 \\
\hline 6 & 50 & 0 & 52 & 0 \\
\hline 7 & 48 & 0 & 55 & 0 \\
\hline 8 & 22 & 0 & 31 & 0 \\
\hline 9 & 50 & 13 & 52 & 13 \\
\hline 10 & 73 & 0 & 94 & 0 \\
\hline 11 & 56 & 0 & 56 & 0 \\
\hline 12 & 50 & 0 & 51 & 0 \\
\hline 13 & 29 & 0 & 31 & 0 \\
\hline 14 & 67 & 0 & 82 & 0 \\
\hline 15 & 15 & 0 & 24 & 0 \\
\hline 16 & 99 & 26 & 92 & 15 \\
\hline 17 & 42 & 0 & 52 & 0 \\
\hline 18 & 29 & 0 & 34 & 0 \\
\hline 19 & 49 & 1 & 56 & 0 \\
\hline 20 & 25 & 0 & 29 & 0 \\
\hline 21 & 41 & 0 & 46 & 0 \\
\hline 22 & 43 & 0 & 55 & 0 \\
\hline 23 & 45 & 0 & 52 & 0 \\
\hline 24 & 59 & 0 & 51 & 0 \\
\hline 25 & 48 & 0 & 48 & 0 \\
\hline 26 & 38 & 1 & 47 & 1 \\
\hline 27 & 56 & 2 & 60 & 0 \\
\hline 28 & 31 & 0 & 37 & 0 \\
\hline 29 & 43 & 0 & 52 & 0 \\
\hline 30 & 38 & 0 & 46 & 0 \\
\hline Mean & $46 \cdot 6$ & $2 \cdot 36$ & 53 & $2 \cdot 17$ \\
\hline
\end{tabular}

TABLE II-Incidence of dietary abuse in 15 patients, acting as their own controls, before and after control and treatment programmes

\begin{tabular}{|c|c|c|c|c|c|c|}
\hline \multirow[b]{2}{*}{ Case No } & \multicolumn{3}{|c|}{ Bulimia } & \multicolumn{3}{|c|}{ Vomiting } \\
\hline & $\begin{array}{l}\text { Before } \\
\text { control } \\
\text { period }\end{array}$ & $\begin{array}{c}\text { Before } \\
\text { treatment, } \\
\text { after } \\
\text { control } \\
\text { period }\end{array}$ & $\begin{array}{c}\text { After } \\
\text { treatment }\end{array}$ & $\begin{array}{l}\text { Before } \\
\text { control } \\
\text { period }\end{array}$ & $\begin{array}{l}\text { Before } \\
\text { treatment, } \\
\text { after } \\
\text { control } \\
\text { period }\end{array}$ & $\begin{array}{c}\text { After } \\
\text { treatment }\end{array}$ \\
\hline
\end{tabular}

\begin{tabular}{rrrrrrr}
\hline 1 & 129 & 120 & 28 & 141 & 136 & 36 \\
3 & 34 & 31 & 0 & 42 & 39 & 0 \\
5 & 18 & 27 & 0 & 26 & 35 & 0 \\
7 & 43 & 48 & 0 & 51 & 55 & 0 \\
9 & 43 & 50 & 13 & 53 & 52 & 13 \\
11 & 57 & 56 & 0 & 59 & 56 & 0 \\
13 & 32 & 29 & 0 & 34 & 31 & 0 \\
15 & 17 & 15 & 0 & 25 & 24 & 0 \\
17 & 29 & 42 & 0 & 40 & 52 & 0 \\
19 & 50 & 49 & 1 & 57 & 56 & 0 \\
21 & 49 & 41 & 0 & 55 & 46 & 0 \\
23 & 29 & 45 & 0 & 41 & 52 & 0 \\
25 & 50 & 48 & 0 & 52 & 48 & 0 \\
27 & 57 & 56 & 0 & 57 & 60 & 0 \\
29 & 39 & 43 & 0 & 49 & 52 & 0 \\
\hline \multirow{2}{*}{ Mean } & $45 \cdot 07$ & $46 \cdot 67$ & $2 \cdot 8$ & $52 \cdot 1$ & $52 \cdot 93$ & $3 \cdot 26$ \\
\hline
\end{tabular}

fell from a mean of 53 episodes to a mean of just over two episodes during the assessment periods $(p<0.01)$. These results include those for two patients (cases 1 and 16) who, although reducing the severity of their symptoms, remained severely afflicted. In fact, 24 patients $(80 \%)$ had stopped binge eating and vomiting completely by the end of the 10 sessions, and a further four patients stopped within four weeks of the end of treatment. This brought the overall initial rate of success to $93 \%$. During the treatment programme, all patients reduced the frequency of their bulimia and associated vomiting attacks. The mean weekly incidence of both symptoms progressively reduced after each treatment session, except for the eighth session (table III). Figure 1 shows this graphically and shows the tendency of symptoms to exacerbate in the latter part of the week as the impact of the treatment session waned.

Mood changes-Full details are outside the scope of this communication. At the beginning of treatment, however, the patients were depressed and angry as judged clinically and as measured on the self rated analogue scales (fig 2). Initial control of the eating disorder was associated with profound mood fluctuations and a feeling of being "disturbed." The last third of the treatment programme was associated with a major reduction in anger, unmasking a nowdeclared depression.

Body weight-The mean presenting weight of the sample was $3.2 \%$ above a mean matched population weight. At the end of the treatment their mean weight was $3.6 \%$ above mean matched popula-
TABLE III-Incidence of bulimia and psychogenic vomiting in 30 patients during the week after each treatment session

\begin{tabular}{lcccccccccc}
\hline Session: & 1 & 2 & 3 & 4 & 5 & 6 & 7 & 8 & 9 & 10 \\
\hline Bulimia & $18 \cdot 5$ & $14 \cdot 4$ & $10 \cdot 3$ & $6 \cdot 2$ & $4 \cdot 5$ & $3 \cdot 2$ & $2 \cdot 0$ & $3 \cdot 3$ & 0.9 & $1 \cdot 5$ \\
Vomiting & $27 \cdot 1$ & $20 \cdot 1$ & $11 \cdot 4$ & $7 \cdot 1$ & $3 \cdot 2$ & $1 \cdot 8$ & $0 \cdot 4$ & $1 \cdot 1$ & $0 \cdot 2$ & $1 \cdot 1$ \\
\hline
\end{tabular}

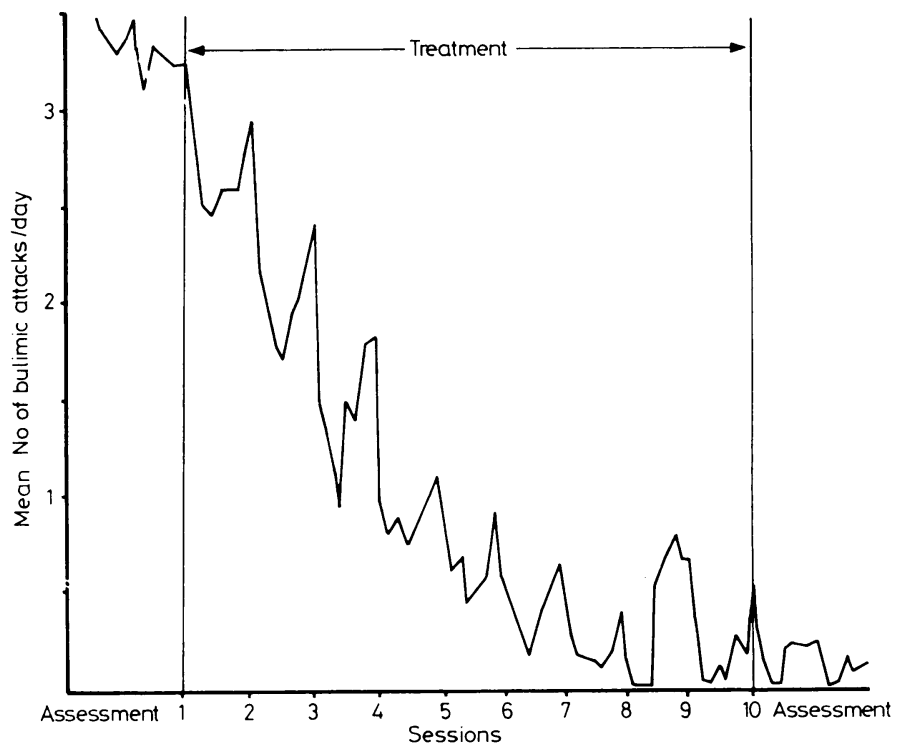

FIG 1-Mean daily incidence of bulimia in 30 patients before, during, and after treatment.

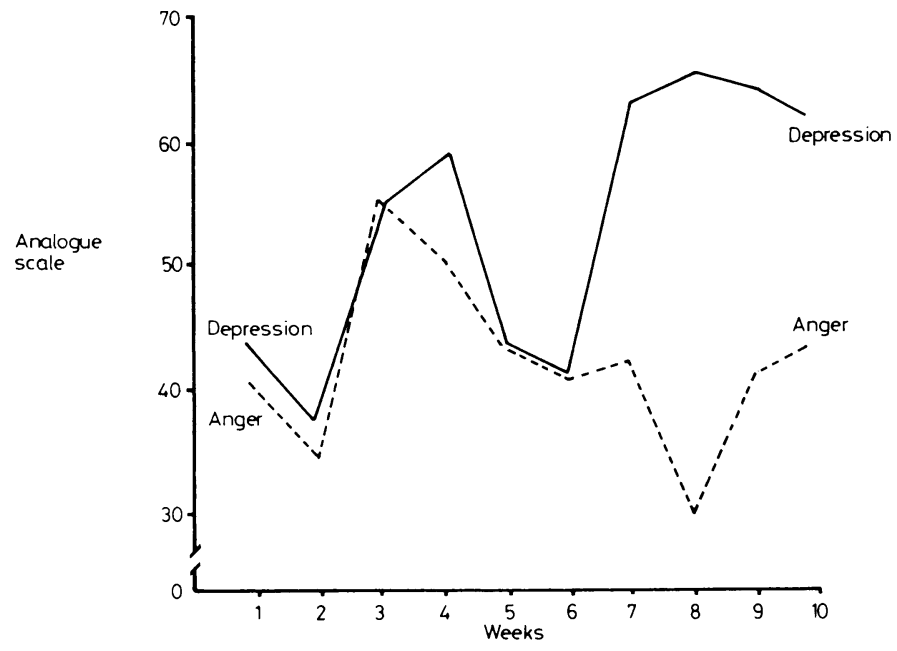

FIG 2-Mean analogue scale scores for depression and anger during each week of treatment.

tion weight and at one year follow up $2.8 \%$ above mean population weight. No patient developed anorexia nervosa or a progressive decompensating obesity.

Follow up-One patient (case 16) refused to attend the follow up clinic, and another needed to be admitted to hospital soon after treatment ended; they were both withdrawn from follow up. Twenty eight patients were monitored in the follow up clinic for up to two years. On average three patients described dietary manipulation in any three month period. The pattern of improvement took two forms. Firstly, 20 patients had no bulimic or vomiting episodes at all. Most of these patients felt the impulse to binge eat but resisted the compulsion. All felt intermittently emotionally "disturbed" and six had considered further psychotherapy. Only one pursued the matter, however, and is now in individual psychotherapy-therapy

8

竝


which is undisturbed by dietary disorder. Secondly, eight patients had occasional bulimic episodes. Before treatment these patients were vomiting, on average, more than four times a day and judged their diet to be in daily "chaos." After treatment these chaotic periods were reduced to a mean of three times a year. The patients themselves judged this to be a satisfactory outcome. Three of these patients requested further psychotherapy, but only two began treatment during the follow up period (at 18 and 22 months). No other patients received further treatment.

Alcohol abuse-A history of alcohol abuse was associated with a poorer outcome. The patient who refused follow up was alcoholic; of the eight who had occasional mild bulimic episodes during follow up, four had a history of alcohol abuse (including two who were alcoholic). Only one of the 20 who had no bulimic or vomiting episodes during follow up had a history of alcohol abuse, and that was mild (table IV).

TABLE IV-Number of patients with alcohol abuse and history of anorexia nervosa in each outcome group

\begin{tabular}{lccc}
\hline \multicolumn{1}{c}{ Outcome group } & $\begin{array}{c}\text { No of } \\
\text { patients }\end{array}$ & $\begin{array}{c}\text { Alcohol } \\
\text { abuse }\end{array}$ & $\begin{array}{c}\text { Previous } \\
\text { anorexia nervosa }\end{array}$ \\
\hline $\begin{array}{l}\text { No bulimic episodes } \\
\text { Mild occasional episodes }\end{array}$ & 20 & 1 & 1 \\
Needed further treatment & 1 & 4 & 3 \\
Refused follow up & 1 & 1 & 1 \\
\hline \multicolumn{1}{c}{ Total } & 30 & 6 & 6 \\
\hline
\end{tabular}

Previous anorexia nervosa-Of the six patients who had had anorexia nervosa only one did not have a bulimic attack during follow up. Furthermore, the two failures in the total sample (cases 1 and 16) had had severe previous anorexia nervosa. Nevertheless, the treatment was still effective for this group: all improved during treatment; four of the six were satisfied with the outcome, either stopping or having only mild bulimic episodes; a further patient (case 1) felt that the outpatient programme allowed her to face inpatient help, something which she had avoided for 16 years and which was successful (table IV).

Pregnancy-Three of the patients became pregnant soon after the end of treatment. None of the patients developed hyperemesis and all had normal deliveries. Dietary abuse did not return after the puerperium. One baby developed projectile vomiting at 10 days and was operated on successfully for proved pyloric stenosis.

Marital difficulties-Married patients experienced difficulties during or shortly after the treatment programme. No marital problems occurred at the end of the control programme. In each case there was a shift in the relationship, generated by anger, when the patient gave up her eating symptoms, leading to the marriage being questioned. One husband was admitted to a psychiatric hospital complaining of depression. The others were treated for depression, gastrointestinal problems, or "stress."

\section{Discussion}

Bulimia is a fluctuating symptom occurring in often suggestable patients. The study was designed to show whether any improvement resulted from the treatment programme or from other factors, such as the intensive assessment, monitoring procedures, knowledge of impending treatment, or the simple passage of time.

The control programme, however, had no effect on the obvious symptoms. The same patients, who acted as their own controls, showed a rapid improvement in symptoms during the treatment programme. The degree of improvement was similar to that in the group who went straight into treatment, suggesting that a period of non-treatment (in effect, being on the waiting list) was not necessary for eventual improvement.

The results of this treatment are good. Although they are the product of the whole programme, certain features are noteworthy. The treatment is eclectic. It draws on behavioural, cognitive, and counselling techniques to bring structure and order to a chaotic eating pattern, but then it shifts gear as treatment progresses to provide psychodynamically orientated therapy. This handles and controls the pronounced tension, anger, and depression which follows giving up the symptoms of bulimia nervosa. It is important that the individual and group therapy sessions should occur on the same afternoon, the one linked and fuelling the other.

The move in the individual sessions from behavioural to psychodynamically orientated therapy is led by the patient herself as she realises that the quicker she brings her symptoms under control the more time is available for insight directed therapy.

The relationship between patient and therapist is not confrontary or authoritarian, but it does put the responsibility for change-that is, getting better-on the patient herself. It cultivates the patient's undoubted motivation. In analytic terms an alliance is formed between the therapist and the rational self of the patient against the dietary and emotional chaos. The group component of the treatment was particularly valued and each group formed a marked and noticeable esprit de corps, which helped patients over difficult patches. This continued after the formal ending of treatment as the patients tended to meet together, forming self help groups and maintaining peer pressure and thereby consolidating improvement.

The dietary diary is perhaps the single most important stratagem that works against the need for hospital admission. It becomes an intensely personal document, symbolising the relationship between therapist and patient: it may, perhaps, be described as a transitional object. The diary provides control and discipline throughout the week and a constantly available outlet for emotional feelings.

The diet sheet emphasises that bulimia can be thwarted by adequate carbohydrates when taken regularly. By giving a choice of other foods, battles of authority between therapist and patient are reduced. It informs the patient of the amount of food needed to maintain her weight-a matter about which she has little knowledge. Perhaps, however, it is the therapist's insistence on the patient maintaining her presenting weight (thereby temporarily removing the drive to diet) which allows the bulimia to stop, under the impact of the programme.

Patients who did well tended to be ambitious, hardworking women whose predominant clinical symptoms, apart from their eating disorder, were sadness and anger-the latter being initially denied. A few had anxiety-phobic features. In general, they appeared to be resourceful yet "neurotic." ?18 On the other hand, a poorer prognosis was associated with abuse of alcohol, severity of bulimia, and, to a lesser extent, previous anorexia nervosa. Experience has shown that personality disorder particularly when associated with alcohol and drug abuse and perhaps, sexual disinhibition, indicates the need for longer and more intense treatment than was given in this programme, the more severe cases needing inpatient treatment. When these indicators are taken into account, the prognosis of bulimic patients is not as poor as originally judged.

This programme is a brief, effective, and cost effective treatment which has the advantage that it can be conducted by paramedical staff under medical supervision. The programme can be set up as part of a general psychiatric service and therefore provides perhaps the best opportunity for the large number of patients at present asking for help. Certainly the cardinal features of this programme-a contract through which the patient agrees to maintain a stabilised weight and a prescribed diet while being held in therapeutic control and given supportive, yet insight directed psychotherapy-is appreciated by patients and is successful. Perhaps most importantly, the results seem to hold with time.

I thank Dr F Moureli, Dr A Powell, Dr M Beary, Miss A Harte, Mrs T Mason, and Farmitalia Carlo Erba for help with this project.

\section{References}

${ }^{1}$ Russell GFM. Bulimia nervosa: an ominous variant of anorexia nervosa. Psychol Med 1979;9:429-48.

2 Bruch H. Eating disorders. London: Routledge and Kegan Paul, 1974. 
${ }^{3}$ Pyle RL, Mitchell JE, Eckert ED. Bulimia: a report of 34 cases. $\mathcal{F}$ Clin Psychiatry $1981 ; \mathbf{4 2}(2): 60-4$.

1 Palmer RL. The dietary chaos syndrome: a useful new term ? $\mathrm{Br} \mathcal{F} \mathrm{Med}$ Psychol 1979;52:187-90.

${ }^{5}$ Diagnostic and statistical manual of mental disorders. 3rd ed. Washington, DC: American Psychiatric Association, 1980.

${ }^{6}$ Crisp AH. Anorexia nervosa at normal body weight. The abnormal normal weight control syndrome. Int $\mathcal{f}$ Psychiatry Med 1982;11(3): 203-33.

${ }^{7}$ Lacey JH. The bulimic syndrome at normal body weight: reflections on pathogenesis and clinical features. International fournal of Eating Disorders $1982 ; 2(1): 59-66$

^ Crisp AH, Palmer RL, Kalucy RS. How common is anorexia nervosa? A prevalence study. Br f Psychiatry 1976;128:549-54.

${ }^{9}$ Lacey JH, Chadbund C, Crisp AH, Whitehead J, Stordy J. Variations in energy intake of adolescent girls. F Hum Nutr 1978;32:419-26.

10 Fairburn CG, Cooper PJ. Self-induced vomiting and bulimia nervosa: an undetected problem. Br Med f 1982;284:1153-5.
${ }^{1}$ Halmi KA, Falk JR, Schwartz E. Binge-eating and vomiting: a survey of a college population. Psychol Med 1981;11:697-706.

12 Garner DM, Garfinkel PE, Bemis KM. A multidimensional psychotherapy for anorexia nervosa. International fournal of Eating Disorders $1981 ; 2: 3-46$.

${ }^{13}$ Fairburn CG. A cognitive behavioural approach to the management of bulimia. Psychol Med 1981;11:707-11.

${ }^{11}$ Feighner JP, Robins E, Guza SB, Woodruff RA, Windur G, Munoz R Diagnostic criteria for use in psychiatric research. Arch Gen Psychiatry $1972 ; 26: 57-63$.

${ }^{15}$ Crisp AH. Anorexia nervosa. Hospital Medicine 1967;1:713-8.

${ }^{16}$ Aitkin RCB, Zealley AK. Measurement of moods. Hospital Medicine $1970 ; 1: 215-44$.

17 Kemsley WFF. Annals of Eugenics 1953;16:316-34

${ }^{18}$ Lacey JH. The patient's attitude to food. In: Lessof $\mathrm{MH}$, ed. Clinical reactions to food. Chichester: John Wiley, 1983.

(Accepted 14 March 1983)

\section{SHORT REPORTS}

\section{Toxic shock syndrome and endocarditis}

The toxic shock syndrome is known to be associated with a variety of staphylococcal infections unrelated to the use of tampons or to menstruation. ${ }^{1}$ We report a case in a patient who had staphylococcal endocarditis.

\section{Case report}

The patient was a 21 year old woman who had been having psychiatric treatment for intravenous drug abuse for the past year. She had had amenorrhoea for three months but was not pregnant. The illness started with fever of $40 \cdot 4 \mathrm{C}$, severe myalgia, and non-productive cough. On admission she was drowsy, pale, and dehydrated and her blood pressure was $90 / 50 \mathrm{~mm} \mathrm{Hg}$ (supine). On clinical examination a soft systolic murmur was heard at the left sternal edge with widespread bilateral crepitations and a harsh pleural rub at the left base. Echocardiography showed vegetations and thickening of the tricuspid valve, and electrocardiography showed a sinus tachycardia of 110 beats/min with extensive $T$ wave inversion in anterior and lateral leads. Patchy consolidation was present at both bases on a chest $x$ ray film, and the left diaphragm was raised.

A provisional diagnosis of endocarditis of the tricuspid valve with pulmonary embolisation was confirmed by the isolation of Staphylococcus aureus from all of four blood cultures. Laboratory investigations showed renal dysfunction with raised blood urea and creatinine concentrations (26.4 $\mathrm{mmol} / 1(159 \mathrm{mg} / 100 \mathrm{ml})$ and $220 \mu \mathrm{mol} / 1(2.5 \mathrm{mg} / 100 \mathrm{ml})$, respectively). There was moderate anaemia (haemoglobin concentration $8.9 \mathrm{~g} / \mathrm{dl}$ ), and platelets were low at $85 \times 10^{9} / 1$. Results of liver function tests were normal

Despite aggressive treatment to achieve volume expansion and correct shock, systolic blood pressures below $90 \mathrm{~mm} \mathrm{Hg}$ were recorded several times in the 24 hours after admission. Thereafter the blood pressure stabilised. She was treated with intravenous cloxacillin ( $12 \mathrm{~g}$ daily) and gentamicin ( $240 \mathrm{mg}$ daily) but remained feverish for nine days. Blood cultures collected during this period remained sterile. Rifampicin $900 \mathrm{mg}$ daily was then substituted for gentamicin and she became afebrile two days later. Eleven days after the onset of illness an erythematous rash appeared over her fingers, and two days later the skin desquamated over the distal two phalanges of the fingers of both hands. She discharged herself on the 28th day but was believed to have remained well.

Bacteriology-The $S$ aureus isolated was phage group II (type 3A/3C/55/ 71 ) and produced enterotoxin F. It was resistant to penicillin but sensitive to methicillin, vancomycin, gentamicin, and rifampicin. Minimal inhibitory and bactericidal concentrations for the isolate (table) showed in vitro toler-

Sensitivity of $S$ aureus associated with the toxic shock syndrome

\begin{tabular}{lcc}
\hline Antibiotic & $\begin{array}{c}\text { Minimal inhibitory } \\
\text { concentration }(\mathrm{mg} / \mathrm{l})\end{array}$ & $\begin{array}{c}\text { Minimal bactericidal } \\
\text { concentration (mg/l) }\end{array}$ \\
\hline Cloxacillin & 0.25 & $>32$ \\
Gentamicin & 0.35 & 0.35 \\
Vancomycin & 0.25 & 0.25 \\
Rifampicin & 0.007 & 0.007 \\
\hline
\end{tabular}

ance to cloxacillin. Bacterial synergy could not be shown in vitro for either of the combinations of antibiotic ultimately used. Carriage of $S$ aureus at other sites was not investigated until after treatment had started and proved negative.

\section{Comment}

We believe this to be the first recorded case of the toxic shock syndrome in association with staphylococcal endocarditis. Although the case was unusual as blood cultures yielded $S$ aureus the patient had the classic features of the disease with fever, hypotension, desquamation, and evidence of multisystem involvement (myalgia, renal impairment, thrombocytopenia, and cardiac abnormalities) as defined by Bergdoll et al. ${ }^{2}$ The staphylococcus isolated was unusual since it belonged to phage group II, a group classically associated with production of epidermolytic toxins $\mathrm{A}$ and $\mathrm{B}$ and the scalded skin syndrome. It failed to produce these toxins but did elaborate enterotoxin $F$, which is characteristic of strains associated with the toxic shock syndrome ${ }^{2} 3$

Tolerance to both nafcillin and vancomycin has been documented in staphylococci associated with the toxic shock syndrome but is rare." The clinical importance of in vitro tolerance remains controversial, but this phenomenon is more important when the syndrome is associated with endocarditis than it is in most cases, in which a bactericidal antimicrobial regimen is not mandatory.

The toxic shock syndrome has emerged as a multifactorial staphylococcal disease and should be considered in all patients with appropriate signs and symptoms regardless of their sex or menstrual state.

We thank Dr Maureen De Saxe, Central Public Health Laboratory, Colindale, and Dr Merlin Bergdoll, University of Wisconsin, Madison, for testing this staphylococcal isolate for epidermolytic toxins and enterotoxins.

${ }^{1}$ Reingold AL, Hargrett NT, Dan BB, Shands KN, Strickland BY, Broome CV. Non-menstrual toxic shock syndrome. Ann Intern Med 1982;96:8714.

2 Bergdoll MS, Crass BA, Reiser RF, Robbins RG, Davis JP. A new staphylococcal enterotoxin, enterotoxin $F$, associated with toxic shock syndrome. Lancet 1981 ; i:1017-21.

${ }^{3}$ Bergdoll MS, Crass BA, Reiser RF, Robbins RG, Davis JP. An enterotoxin-like protein in Staphylococcus aureus strains from patients with toxic shock syndrome. Ann Intern Med 1982;96:969-71.

4 Chesney PJ, Crass BA, Pulyak MB, et al. Toxic shock syndrome-management and long term sequelae. Ann Intern Med 1982;96:847-51.

(Accepted 15 March 1983)

Departments of Bacteriology and Medicine, Royal Infirmary, Glasgow G4 OSF

$M$ WHITBY, MB, FRACP, senior registrar in microbiology

$S$ FRASER, MB, MRCP, registrar in medicine

C G GEMMELL, PHD, MIBIOL, senior lecturer in bacteriology

P A WRIGHT, MB, MRCPATH, consultant microbiologist

Correspondence to: $\operatorname{Dr} M$ Whitby. 